\title{
Nutritional status and vitamin $A$ and zinc levels in patients with kala-azar in Piauí, Brazil
}

\author{
Mísia Joyner de Sousa Dias Monteiro[1], Maria Nauside Pessoa da Silva ${ }^{[2]}$, \\ Adriana de Azevedo Paiva ${ }^{[3]}$, Dilina do Nascimento Marreiro ${ }^{[3]}$, Liania Alves Luzia ${ }^{[4]}$, \\ Gilberto Simeone Henriques ${ }^{[5]}$, Patrícia Helen de Carvalho Rondó[ ${ }^{[6]}$, Ingridi de Souza Sene ${ }^{[7],[8]}$, \\ Ana Tárcila Alves de Almeida ${ }^{[9]}$, Carlos Henrique Nery Costa ${ }^{[7],[10],[11]}$ \\ and Dorcas Lamounier Costa ${ }^{[7],[10],[12]}$
}

\begin{abstract}
[1]. Universidade Federal do Piauí, Mestrado em Ciências e Saúde, Teresina, PI, Brasil.
[2]. Universidade Federal do Piauí, Programa de Pós-Graduação em Biotecnologia, Rede Nordeste de Biotecnologia, Teresina, PI, Brasil.

[3]. Universidade Federal do Piauí, Departamento de Nutrição, Teresina, PI, Brasil.

[4]. Universidade de São Paulo, Laboratório de Micronutrientes, São Paulo, SP, Brasil.

[5]. Universidade Federal de Minas Gerais, Escola de Enfermagem, Laboratório Experimental de Nutrição, Belo Horizonte, MG, Brasil.

[6]. Universidade de São Paulo, Departamento de Nutrição, Escola de Saúde Pública, São Paulo, SP, Brasil.

[7]. Universidade Federal do Piaú, Laboratório de Pesquisas em Leishmanioses, Teresina, PI, Brasil.

[8]. Laboratório de Anatomia Patológica e Biologia Molecular, Teresina, PI, Brasil.

[9]. Universidade Federal do Piauí, Curso de Farmácia, Teresina, PI, Brasil.

[10]. Centro de Inteligência para Agravos Tropicais Emergentes e Negligenciados, Teresina, PI, Brasil.

[11]. Universidade Federal do Piauí, Departamento de Medicina Comunitária, Teresina, PI, Brasil.

[12]. Universidade Federal do Piauí, Departamento Materno-Infantil, Teresina, PI, Brasil.
\end{abstract}

\begin{abstract}
Introduction: Malnutrition and kala-azar (or visceral leishmaniasis) are significant public health problems in different parts of the world. Immunity and susceptibility to infectious and parasitic diseases are directly linked to the host's nutritional state, but little is known about the interaction between nutrition and kala-azar. This study aimed to evaluate nutritional status with kala-azar and correlate these findings with the clinical and laboratory manifestations of the disease, and zinc and retinol levels. Methods: This was a cross-sectional study of 139 patients with kala-azar. Nutritional status classification was performed according to international recommendations. Parametric or nonparametric tests were applied whenever indicated in a two-sided test with a 5\% significance level. Results: Weight loss and malnutrition were more frequent in adults. Body mass index-for-age, fat area of the arm, and upper arm muscle area were significantly associated with probability of death. The presence of human immunodeficiency virus, hepatomegaly, and splenomegaly was correlated with nutritional assessment. Blood leukocyte and lymphocyte, serum creatine, and vitamin A levels were significantly higher in adult men. Vitamin A levels were highly associated with the level of hemoglobin and C-reactive protein (CRP) in multivariate analysis. All patients had reduced plasma zinc levels, but this finding had no association with the outcome variables. Conclusions: Malnutrition was correlated with severe disease and was more prevalent in older people with kala-azar. Vitamin A deficiency was associated with hemoglobin and CRP. Zinc levels were reduced in patients with kala-azar.
\end{abstract}

Keywords: Leishmaniasis. Visceral. Kala-azar. Malnutrition. Vitamin A. Zinc.

Corresponding author: Dr. Dorcas Lamounier Costa.

e-mail: dorcas.lc@gmail.com

(D) https://orcid.org/0000-0001-7115-7978

Received 27 November 2020

Accepted 26 July 2021

\section{INTRODUCTION}

Kala-azar or visceral leishmaniasis (VL) is caused by Leishmania infantum protozoa in the Americas and is transmitted by infected female phlebotomine Lutzomyia. The signs and symptoms of VL include fever, hepatosplenomegaly, weight loss, and pancytopenia in most patients. If not treated, this disease can be lethal. The factors associated with a higher risk of death are the presence of anemia, 
jaundice, edema, bleeding disorders, bacterial infection, and human immunodeficiency virus (HIV) coinfection ${ }^{1-3}$. Approximately half of kala-azar patients in Brazil are children under the age of five $e^{4}$. Death is usually associated with systemic inflammation, bleeding, and bacterial infections. Immunity and susceptibility to infections and parasitic diseases are correlated with nutritional status.

Malnutrition and infection are intrinsically linked, and this interaction results in the worsening of both. The role of nutrition in the prevention of disease and the reduction of morbidity and mortality is evident, particularly in regions with a high prevalence of infectious diseases, such as tuberculosis, leishmaniasis, HIV, and malaria ${ }^{5}$.

The World Health Organization (WHO) and the World Bank Group estimate that 462 million people are underweight and that 1.9 billion adults ( $>18$ years of age) are overweight/obese. Furthermore, 52 million children ( $<5$ years of age) are wasted, with $\sim 17$ million severely wasted, 155 million stunted, and 41 million overweight ${ }^{6}$. According to estimates, there are 0.2 to 0.4 million VL cases with an overall case-fatality rate of $10 \%$.

Malnutrition increases susceptibility to infections, such as leishmaniasis, and determines the severity of illness by several etiologic pathways in cases of under- and overnutrition: immune dysfunction, decreased epithelial integrity, altered metabolic rate, chronic inflammation, and altered dietary absorption. The interactions between nutritional status and infectious disease is complex because it involves interactions between the host, pathogens, and the environment ${ }^{8}$.

Although malnutrition has been associated with a higher probability of infection by Leishmania spp., the mechanisms involved in the relationship between nutrition and human VL evolution are poorly explained ${ }^{9}$. It is unclear whether malnutrition is a risk factor for kala-azar or a consequence of the protracted consumption process ${ }^{9-12}$.

Selective or combined deficiencies of micronutrients or trace elements can contribute to worsening and delayed recovery from infectious and chronic diseases ${ }^{13,14}$. Vitamin A (VitA) has health-promoting and regulatory activities in both the innate and adaptive immune systems; therefore, it can improve immune function and enhance defense against many infectious diseases ${ }^{15,16}$. VitA supplementation has been shown to prevent respiratory and diarrheal deaths in many countries ${ }^{17}$. Serum retinol levels are lower in individuals with kala-azar ${ }^{18,19}$, but the role of the immune system in the evolution of the disease is still unclear.

Several minerals are associated with an impaired immune system. Zinc plays a fundamental role in the production or biological activity of several interleukins, which, in turn, influences the development and functions of T and B lymphocytes, macrophages, and NK cells. Helper T cells Th1 and Th2, which promote resistance to infections, are also affected by reduced zinc levels ${ }^{20,21}$. Additionally, studies have shown that serum zinc levels are lower in people with kala-azar ${ }^{22}$.

The objective of this study was to assess the nutritional status and VitA and zinc levels of patients with kala-azar and to correlate it with the clinical presentation of the disease.

\section{METHODS}

\section{Patients}

This study was conducted at the Natan Portella Tropical Diseases Institute in Teresina, Piauí, Brazil, from June 2018 to August 2019. Individuals of all ages and both sexes who presented with fever, splenomegaly, weight loss, or paleness and had previously undergone bone marrow puncture were included. Anamnesis and physical examinations were performed during the first 24 hours of hospitalization. The liver and spleen were measured by palpation and percussion during physical examination. Kalaazar was confirmed by a positive parasitic test (via microscopy or culture of Leishmania sp. in a Novy-McNeal-Nicolle medium or via polymerase chain reaction). An immunochromatographic test was conducted when the first tests could not be performed, and the diagnostic suspicion was high.

\section{Nutritional evaluation}

Anthropometry was conducted by following the protocol of the Laboratory for Nutritional Evaluation of Population $\mathrm{s}^{23}$ and by using data from the National Health and Nutrition Examination Survey (CDC, 2017) ${ }^{24}$. The percentage of body weight loss during illness was calculated if information on weight at the onset of symptoms was available. Weight-for-age, height-for-age, body mass index (BMI), and respective percentiles and Z-scores were calculated using Anthro and AnthroPlus software (WHO, 2009). The muscular and fat areas of the arm were determined according to the proposal of Frisancho ${ }^{25}$.

\section{Laboratory tests}

Laboratory tests included blood count (laser flow cytometry), erythrocyte sedimentation rate (Westergreen method), aminotransferase dosage (Technicon automation method), bilirubin (colorimetric method), creatinine (Jaffé reaction), urea (Berthelot urase), alkaline phosphatase (Bowers \& McComb), albumin and globulin (bromocresol green), C-reactive protein (CRP) (nephelometry), summary test (Uri-test 11), and urine culture. The laboratory reference value (accreditation by the General Coordination for Accreditation and the Institute National Metrology, Quality, and Technology [INMETRO, Brazil]) served as a reference for the laboratory results. Screening for HIV was part of the investigation of suspected kala-azar patients. Risk of death was calculated using KalaCal ${ }^{\circledR}$ software $^{1}$. VitA and serum and erythrocyte zinc measurements were performed as proxies for micronutrient malnutrition and followed published protocols ${ }^{26}$.

\section{Retinol measurement}

Serum retinol was measured using a high-performance liquid chromatography LC-20AT model equipped with an SIL20AC automatic injector, a CBM-20A system controller, and an SPD-M20A controller diode array detector (Shimadzu Inc. Tokyo, Japan). We defined "VitA deficiency" as VitA levels below 0.35 $\mu \mathrm{mol} / \mathrm{L}$, "low VitA levels" as between 0.35 and $0.70 \mu \mathrm{mol} / \mathrm{L}$, and "sufficient VitA levels" as below $0.70 \mu \mathrm{mol} / \mathrm{L}^{27}$. 


\section{Zinc measurement}

Zinc levels were analyzed by an inductive plasma spectrometer and optic emission spectrometry with an axial view configuration and a V-Groove nebulizer (720 ICP/OES, Varian Idc., California, USA). The spectral line used for zinc measurement was 213.856 $\mathrm{nm}$. Samples of certified reference material and Seronorm ${ }^{\mathrm{TM}}$ Oligoelement Serum L-1 and L-2 (Billingstad, Norway) were used to validate the analytical measurements. The spectral line used for zinc measurement was $213.856 \mathrm{~nm}$. Samples of certified reference material and Seronorm ${ }^{\mathrm{TM}}$ Oligoelement Serum L-1 and L-2 (Bill, instead, Norway) were used to validate the analytical measurements. The cutoff points for plasma zinc adequacy and erythrocyte zinc adequacy were 75 to $110 \mu \mathrm{g} / \mathrm{dL}$ and 40 to $44 \mu \mathrm{g} / \mathrm{g}$ $\mathrm{Hb}$, respectively ${ }^{28,29}$.

\section{Ethical board approval}

The Research Ethics Committee of the Federal University of Piauí approved the study (No. 2.445.702). Each participant or his legal representative signed an informed consent form.

\section{Statistical analysis}

Nutritional analysis followed the definitions of the $\mathrm{WHO}^{30,31}$ and Health Ministry/System for Food and Nutritional Vigilance ${ }^{32}$. Categorical variables were analyzed using proportions. Quantitative data are presented as means, medians, confidence intervals (CIs), or interquartile intervals. Percentiles Z-scores and dispersion are presented as standard deviations of minimum-maximum intervals. The association of categorical variables was evaluated using a chi-square test and Fisher's exact tests. The correlation between normally distributed variables was evaluated using the Pearson correlation coefficient or Spearman correlation test when the variables were not normally distributed. A t-test was performed to compare the means of normally distributed continuous variables, and the Wilcoxon rank-sum test was used to compare nonnormally distributed continuous variables. The VitA deficiency odds ratios for clinical and laboratory data were calculated using univariate and logistic multivariate analyses. The normality of numeric variables was visualized in dispersion graphs and evaluated using kurtosis and skewness tests. A 5\% significance level for two-sided tests was considered in all analyses of VitA deficiency between the clinical and laboratory variables

\section{RESULTS}

A total of 139 individuals were recruited: $102(73.4 \%)$ were male, and $37(26.6 \%)$ were female $(p<0.001)$. Age distribution was bimodal with a mean of 4.3 years $(95 \%$ CI $3.3-5.4)$ in individuals under 18 years old and 39.0 years (95\% CI 35.9-42.1) among individuals aged 18 years old or older. One hundred eight participants (77.7\%) were from Piauí, 29 (20.9\%) were from Maranhão, and 2 (1.4\%) were from Bahia. Ninety-nine individuals $(71.2 \%)$ lived in urban areas, and $40(28.8 \%)$ lived in rural areas $(p<0.001)$. Seven $(5.04 \%)$ patients died during hospitalization. Ninety-seven participants $(69.8 \%)$ were diagnosed by parasitological diagnosis (microscopy or culture), and 42 (30.2\%) were diagnosed by rapid immunochromatographic test (rapid test). A confirmatory molecular test revealed that 13 of 42 patients were positive; thus, 12 of 42 patients were diagnosed only by rapid testing. The mean time between the onset of symptoms until the diagnosis was 30.5 days (95\% CI 24.9-36.2). Treatment for kala-azar was performed with pentavalent antimonial in 68 participants $(48.9 \%)$ and with liposomal amphotericin in 71 participants (51.1\%).

The main signs and symptoms identified at hospital admission were fever, pallor, apathy, fatigue, and chills. The most frequent laboratory changes were anemia and leukopenia. Table 1 presents the demographic and clinical characteristics of the study population.

\section{Nutritional analysis}

Nutritional assessment according to age group (children under 5 years old, children between 5 and 10 years old, children 10 to 20

TABLE 1: Demographic and clinical characteristics of the study population.

\begin{tabular}{|c|c|c|}
\hline Characteristic & $\mathbf{n}$ & $\%$ \\
\hline \multicolumn{3}{|l|}{ Sex } \\
\hline Male & 102 & 73.4 \\
\hline Female & 37 & 26.6 \\
\hline \multicolumn{3}{|l|}{ Age $(\mathrm{m}, 95 \% \mathrm{Cl})^{1}$} \\
\hline < 18 y.o. & 4.3 & $3.3-5.4$ \\
\hline$\geq 18$ y.o. & 39.0 & $35.9-42.1$ \\
\hline \multicolumn{3}{|l|}{ Origin } \\
\hline Urban & 99 & 71.2 \\
\hline Rural & 40 & 28.8 \\
\hline \multicolumn{3}{|l|}{ Diagnostic method } \\
\hline Parasitological & 97 & 69.8 \\
\hline Molecular & 30 & 21.6 \\
\hline Immunological & 12 & 8.6 \\
\hline Duration of illness (days) $)^{2}(\mathrm{~m}, 95 \% \mathrm{Cl})$ & 30.5 & $24.9-36.2$ \\
\hline \multicolumn{3}{|l|}{ Signs and symptoms } \\
\hline Fever & 133 & 95.7 \\
\hline Anemia & 133 & 95.7 \\
\hline Splenomegaly & 135 & 97.1 \\
\hline Thrombocytopenia & 99 & 71.2 \\
\hline Neutrophils $<1000 \mathrm{cel} / \mathrm{mm}^{3}$ & 60 & 43.1 \\
\hline $\mathrm{CRP}^{3}>10 \mathrm{mg} / \mathrm{dL}$ & 133 & 95.7 \\
\hline $\mathrm{CRP}>50 \mathrm{mg} / \mathrm{dL}$ & 81 & 60.9 \\
\hline \multicolumn{3}{|l|}{ Risk of death ${ }^{4}$} \\
\hline$>0.10$ & 34 & 26.5 \\
\hline$>0.30$ & 8 & 5.8 \\
\hline
\end{tabular}

${ }^{1}$ age (mean, $95 \%$ confidence interval); ${ }^{2}$ Days from first symptoms to diagnosis; ${ }^{3} \mathrm{C}$-reactive protein; ${ }^{4}$ Risk of death calculated by KalaCal ${ }^{\circledR}$ software. 
years old, adults, and elderly) is presented in the supplemental material (Supplemental Tables 1 to 4). Children and adolescents had a higher prevalence of malnutrition when assessed by weight-for-age than by height and BMI-for-age. Adults and the elderly had a BMI below normal limits and a higher prevalence of malnutrition than younger patients. Supplemental Figure 1 shows the graphs of weight-for-age, height-for-age, and BMI-for-age in children and adolescents, with the curves of weight-for-age and height-for-age shifted to the left.

One hundred and five patients (77.0\%) reported their body weight before getting sick, and $82(78.1 \%)$ had weight loss. There was a positive correlation between the percentage of weight loss and age $(\mathrm{r}=0.29 ; p=0.003)$, thus indicating that adults lost more weight than children.

Given that the population in this study comprised individuals from early childhood to old age, it was necessary to adopt a unified index to compare nutritional data for all ages. The BMI was adapted in three categories in each age group to define malnutrition, eutrophy, and overweight or obesity. After applying this interpretation to the nutritional diagnosis, we found that 23 participants $(16.79 \%)$ were malnourished, 93 (67.88\%) were eutrophic, and 21 (15.33\%) had weights above the eutrophic limits (Supplemental Table 5).

The mean age of the female participants was higher than that of the male participants $(p=0.007)$. The mean brachial circumference and skinfold were significantly lower in women, except for the subscapular fold and brachial fat percentage (Table 2). Data on brachial circumference and skinfolds were missing in some participants because of their refusal to undergo measurements. A sensitivity analysis was then performed to verify whether the loss of information would have been different. There was no difference in sex, main signs and symptoms, and laboratory tests between the groups with and without this measurement. Thus, the analysis was considered viable. Brachial circumference was the most sensitive parameter to detect malnutrition, with 83 participants $(66.9 \%)$ below the 5 th percentile.
Table 3 shows the correlation analysis of the BMI classification according to age, upper arm muscle, and arm fat area with clinical and laboratory data. A positive correlation was observed between nutritional indicators and percentage of body weight lost during the disease, neutrophil and serum creatinine levels, and splenomegaly. Nutritional status was negatively correlated with hepatomegaly, leukocyte count, and lymphocyte count.

Men had a higher BMI, larger arm muscle area $(p=0.002)$, and larger upper arm muscle area $(p=0.01)$ than women, but there was no correlation between fat area and sex. There was a correlation between BMI adjusted for age ( $p=0.02)$, muscle mass of the arm $(p=0.0001)$, and fat area of the arms $(p=0.002)$ when the groups were compared in terms of lethal outcome and probability of death. The presence of HIV infection, bacterial infection, or bleeding was not correlated with anthropometric variables.

\section{HIV-coinfected patients}

Seventeen patients $(12.2 \%)$ were coinfected with HIVLeishmania. One HIV-coinfected patient was a 58 -year-old malnourished male who had a prolonged febrile disease and died during VL treatment. The 12 remaining HIV-coinfected patients $(92.3 \%)$ were adult males aged $25-58$ years old. Malnutrition was correlated with HIV coinfection $(p=0.01)$, but there was no correlation when the analysis was controlled for age $(p=0.54)$.

\section{Vitamin A}

The mean level of VitA was 1.00 ?mol/L (95\% CI 0.89-1.11). Considering the cutoff point of 0.75 ?mol/L, which includes individuals with deficient and low levels, 67 (48.2\%) and $72(51.8 \%)$ individuals were classified as sufficient and insufficient, respectively. Table 4 presents the association between VitA levels and the relevant clinical and laboratory variables. VitA levels were negatively associated with high levels of CPR $(p=0.002)$ and positively associated with hemoglobin levels below $9 \mathrm{mg} / \mathrm{mL}(p=0.004)$.

TABLE 2: Anthropometric measurements according to the sex of 139 individuals with kala-azar.

\begin{tabular}{|c|c|c|c|c|c|c|c|}
\hline \multirow[t]{2}{*}{ Variables } & \multicolumn{2}{|c|}{ Male } & \multicolumn{2}{|c|}{ Female } & \multicolumn{2}{|c|}{ Total } & \multirow[b]{2}{*}{$p$-value } \\
\hline & mean & $95 \% \mathrm{Cl}$ & mean & $95 \% \mathrm{Cl}$ & mean & $95 \% \mathrm{Cl}$ & \\
\hline Age (years) & 24.0 & $20.0-28.0$ & 13.9 & 8.5-19.3 & 21.3 & $18.0-25.0$ & 0.007 \\
\hline Age $<14$ & 4.5 & $3.1-5.9$ & 4.0 & $2.3-5.8$ & 4.35 & $3.3-5.4$ & 0.66 \\
\hline Age $\geq 14$ & 39.4 & $35.8-42.9$ & 37.2 & $32.2-42.1$ & 39.0 & $35.9-42.1$ & 0.38 \\
\hline BMI $\left(\mathrm{Kg} / \mathrm{m}^{2}\right)$ & 19.2 & $18.4-20.1$ & 17.1 & $15.9-18.4$ & 18.6 & $17.9-19.4$ & 0.01 \\
\hline $\mathrm{BC}(\mathrm{cm})$ & 20.6 & $19.4-21.8$ & 17.5 & $15.5-19.5$ & 19.8 & $18.8-20.9$ & 0.01 \\
\hline TSF (cm) & 7.4 & $6.3-8.5$ & 10.0 & $7.7-12.2$ & 8.0 & $7.0-9.0$ & 0.03 \\
\hline $\mathrm{SSF}(\mathrm{cm})$ & 7.9 & $7.0-8.6$ & 8.4 & $5.7-11.1$ & 7.9 & $7.1-8.8$ & 0.57 \\
\hline $\mathrm{BMC}(\mathrm{cm})$ & 19.5 & $18.4-20.6$ & 15.2 & $13.5-16.9$ & 18.5 & $17.5-19.5$ & 0.0001 \\
\hline $\mathrm{BA}\left(\mathrm{cm}^{2}\right)$ & 36.3 & $32.2-40.4$ & 26.7 & $20.0-33.3$ & 33.9 & $30.4-37.4$ & 0.02 \\
\hline $\mathrm{BFA}\left(\mathrm{cm}^{2}\right)$ & 7.4 & $6.2-8.8$ & 9.5 & $6.2-12.7$ & 8.0 & $6.7-9.2$ & 0.18 \\
\hline$\%$ BFA & 18.8 & $17.1-20.5$ & 29.7 & $26.5-32.9$ & 21.5 & $19.8-23.2$ & $<0.0001$ \\
\hline
\end{tabular}

Student t-test. BC: Brachial circumference; TSF: Triceps skinfold; SSF: Subscapular skinfold; BMC: Brachial muscle circumference; BA: Brachial area; BFA: Brachial fat area; \% BFA: Percentage of brachial fat area; Cl: confidence interval; BMI: body mass index. 
TABLE 3: Correlation of BMI for age, upper arm muscle area, and upper arm fat area with clinical and laboratory variables.

\begin{tabular}{|c|c|c|c|c|c|c|}
\hline \multirow[t]{2}{*}{ Parameter } & \multicolumn{2}{|c|}{${ }^{1} \mathrm{BMI}$ for age } & \multicolumn{2}{|c|}{ Upper arm muscle area } & \multicolumn{2}{|c|}{ Upper arm fat area } \\
\hline & $\mathbf{r}$ & $p$-value & $\mathbf{r}$ & $p$-value & $\mathbf{r}$ & $p$-value \\
\hline${ }^{2}$ weight loss (grams) & 0.16 & 0.09 & -0.22 & 0.04 & 0.03 & 0.73 \\
\hline Spleen extension (cm) & 0.14 & 0.16 & -0.24 & 0.03 & -0.21 & 0.03 \\
\hline Liver extension $(\mathrm{cm})$ & -0.02 & 0.80 & -0.04 & 0.72 & -0.33 & 0.005 \\
\hline Leukocytes (cels/mm³) & -0.23 & 0.006 & -0.30 & 0.0008 & 0.20 & 0.04 \\
\hline Neutrophils (cels/mm³) & 0.17 & 0.05 & 0.05 & 0.53 & 0.17 & 0.10 \\
\hline Lymphocytes (cels $/ \mathrm{mm}^{3}$ ) & -0.17 & 0.04 & -0.41 & $<0.0001$ & -0.31 & 0.001 \\
\hline Platlets $\left(\right.$ cels $\left./ \mathrm{mm}^{3}\right)$ & 0.01 & 0.90 & 0.06 & 0.46 & 0.04 & 0.67 \\
\hline${ }^{3} \mathrm{CRP}(\mathrm{mg} / \mathrm{L})$ & 0.11 & 0.22 & 0.21 & 0.04 & 0.19 & 0.06 \\
\hline Serum creatinine & 0.24 & 0.02 & 0.67 & $<0.0001$ & 0.30 & 0.01 \\
\hline Erythrocyte zinc (mg/dL) & -0.01 & 0.86 & -0.01 & 0.99 & -0.06 & 0.54 \\
\hline
\end{tabular}

Pearson test. 'BMI: body mass index; ${ }^{2}$ Percentage of weight lost during illness; ${ }^{3} \mathrm{C}$-reactive protein.

TABLE 4: Mean levels of vitamin A, and association of vitamin A deficiency with clinical and laboratory variables.

\begin{tabular}{|c|c|c|c|c|c|c|c|c|}
\hline & \multirow{2}{*}{\multicolumn{4}{|c|}{ Serum Vitamin A }} & \multicolumn{4}{|c|}{${ }^{4}$ Vitamin A deficiency } \\
\hline & & & & & \multicolumn{2}{|c|}{ Univariate analysis } & \multicolumn{2}{|c|}{ Multivariate analysis } \\
\hline & $n=138$ & mean (mmol / L) & $95 \% \mathrm{Cl}$ & ${ }^{1} p$-value & Odds ratio & ${ }^{2} p$-value & Odds ratio & ${ }^{3} p$-value \\
\hline \multicolumn{9}{|l|}{ Sex } \\
\hline Male & 102 & 1.11 & $0.92-1.31$ & 0.04 & 0.46 & 0.05 & 0.34 & 0.26 \\
\hline Female & 36 & 0.72 & $0.51-0.93$ & & & & & \\
\hline \multicolumn{9}{|l|}{ Age } \\
\hline$<18$ y.o. & 71 & 0.88 & $0.69-1.09$ & 0.11 & 1.60 & 0.17 & 2.15 & 0.38 \\
\hline$\geq 18$ y.o. & 67 & 0.97 & $0.90-1.38$ & & & & & \\
\hline \multicolumn{9}{|c|}{ HIV coinfection } \\
\hline Absent & 121 & 1.02 & $0.85-1.20$ & 0.78 & 2.95 & 0.20 & - & - \\
\hline Present & 17 & 0.96 & $0.62-1.30$ & & & & & \\
\hline \multicolumn{9}{|c|}{ Hemoglobin (mg/dL) } \\
\hline$<9$ & 38 & 0.66 & $0.45-0.87$ & 0.007 & 1.35 & 0.002 & 6.58 & 0.004 \\
\hline$\geq 9$ & 101 & 1.15 & $0.95-1.35$ & & & & & \\
\hline \multicolumn{9}{|c|}{${ }^{5} \mathrm{CRP}$ (mg/L) } \\
\hline$\geq 50$ & 103 & 0.91 & $0.70-1.12$ & 0.07 & 0.49 & 0.04 & 0.12 & 0.008 \\
\hline$<50$ & 29 & 1.20 & $0.95-1.46$ & & & & & \\
\hline \multicolumn{9}{|c|}{ Albumin (g/dL) } \\
\hline$<2.5$ & 29 & 0.89 & $0.20-1.83$ & 0.54 & 2.68 & 0.11 & 3.03 & 0.16 \\
\hline$\geq 2.5$ & 25 & 1.47 & $0.90-1.58$ & & & & & \\
\hline
\end{tabular}

${ }^{1}$ Student t- test; ${ }^{2} \mathrm{Chi}$-square test; ${ }^{3}$ Logistic regression. ${ }^{4}$ Vitamin A level $<75 \mu \mathrm{mol} / \mathrm{L} ;{ }^{5} \mathrm{C}$-reactive protein; Cl: confidence interval.

\section{Zinc}

Serum zinc levels were measured in 138 participants. The expected serum zinc values would be above $59 \mu \mathrm{g} / \mathrm{dL}$ for women and above $61 \mu \mathrm{g} / \mathrm{dL}$ for men. Zinc levels ranged from 30.9 to $44.9 \mu \mathrm{g} / \mathrm{dL}$ and were below the minimum limit of normality in all individuals. The mean erythrocyte zinc level was 38.14 (95\% CI $37.7-38.5)$, and the mean plasma zinc level was $57.1 \%$ (95\% CI 56.4-57.8). The minimum and maximum values were 48.4 and 66.8 , respectively; therefore, all participants had plasma zinc levels below the minimum limit value. Erythrocyte zinc levels were statistically higher in HIV-coinfected patients than in noncoinfected ones (39.1 
$\mu \mathrm{g} / \mathrm{dL}$ versus $38.0 \mu \mathrm{g} / \mathrm{dL}$ ), although all measurements were below the minimum values. Likewise, plasma zinc levels were also statically higher in coinfected patients than in noncoinfected ones $(57.3 \mu \mathrm{g} / \mathrm{dL}$ versus $56.1 \mu \mathrm{g} / \mathrm{dL})$. Erythrocyte zinc was statistically associated with serum urea $(\mathrm{r}=-0.24, p=0.02)$, but it was not associated with other clinical, laboratory, demographic, housing, and sanitation variables.

\section{DISCUSSION}

Malnutrition, which is often present in individuals with kalaazar, is poorly understood. The population of this study was similar to the literature descriptions, with both sexes equally represented from childhood to adolescence and with men's predominance in adulthood ${ }^{1,33-36}$. The age distribution was bimodal, with a higher mortality rate in young children and older people; this finding is possibly correlated with testosterone levels in adult men. Sex hormones, such as androgens, estrogens, and progestins can interact directly with the immune system and affect immune responses. Macrophages and lymphocytes, which are the two main types of cells involved in the outcome of leishmaniasis, both have receptors for sex hormones ${ }^{37}$. There was a higher frequency of kala-azar in participants residing in urban areas $(99$ [71.2\%]) than in those living in rural areas (40 [28.8\%]). This pattern of urbanization has been verified for at least four decades $\mathrm{s}^{38-40}$. The severity of the disease can be inferred by the proportion of participants who presented with severe anemia, leukopenia, and thrombocytopenia, as described by several authors ${ }^{1,12,35,36,41,42}$. The levels of CRP were above $10 \mathrm{mg} / \mathrm{dL}$ in $95.7 \%$ of the participants, thus indicating acute inflammation; this result is similar to that of other studies ${ }^{18,41}$. The time elapsed from the onset of symptoms to diagnosis in individuals with VL in Brazil in the last few decades or in rural areas before the emergence of urban epidemics in Brazil was significantly less than that in the Old World ${ }^{36,43,44}$. Kala-azar in the Americas evolves into a severe disease that requires hospitalization and diagnosis sooner than in the Old World, and the time it takes for chronic protein-calorie malnutrition to occur is insufficient in the same proportion. The duration of symptoms until diagnosis was 30.5 days, whereas the mean time of the nonurban VL varied from a few weeks to many months ${ }^{45}$.

Proportional weight loss in this study correlated positively with the individual's age even when corrected by body weight before the illness, contrary to the literature, which shows greater vulnerability to nutritional deterioration in children ${ }^{36,42,43}$. There was a high prevalence of malnutrition in all age groups, as reported by other authors ${ }^{18,43}$. In addition, a higher prevalence has been reported in the Old World ${ }^{46,47}$. The evaluation of nutritional status on the basis of arm circumference, which is a parameter that can serve as an index of fat reserve and muscle mass, showed that $66.9 \%$ of people with kala-azar were malnourished ${ }^{18}$. In addition, by measuring the triceps skinfold, which allows for the identification of subcutaneous fat, $46 \%$ of individuals with kala-azar were malnourished or at risk of malnutrition. The analysis of the association between the various nutritional parameters and the clinical and laboratory variables was very similar when the BMI, muscular area, or fat area of the arm was considered, thus showing that malnutrition in patients with kala-azar involves both muscle loss and fat loss.
HIV coinfection was statistically associated with few outcome variables, such as BMI and VitA levels, but did not have clinical relevance. Furthermore, this association was not verified by multivariate analysis.

The association of serum VitA levels with age, sex, HIV coinfection, and disease severity was confounded by BMI, thus highlighting the great value of nutrition in this severe disease. These findings follow published studies that found that most kala-azar patients had low serum VitA levels ${ }^{18,19,48}$. In the current study, there was a moderate-to-strong correlation between VitA levels and age in years. This result is in line with an analysis of healthy children aged 6-13 years in China ${ }^{49}$. Breast milk remains an essential source of VitA in breastfed children from 7 to 12 months, but the national VitA supplementation program of the Ministry of Health of Brazil recommends that children from 6 to 59 months old receive preventive megadose of VitA, which may have interfered with the result ${ }^{50}$.

VitA levels were significantly higher in men than in women in adulthood. However, when VitA sufficiency status was compared in each stratum, the difference only existed between men and women aged between 18 and 50 years, with $50 \%$ of women at this age having low levels of retinol. Weight was associated with VitA levels in women of reproductive age. The data in this study are similar to those of a clinical trial in which $40 \%$ of postpartum women had low VitA status and more than one-tenth had evidence of VitA deficiency ${ }^{51}$. Low VitA levels were associated with a probability of death greater than 0.10 , but there was no association when the cutoff point of mortality was 0.3 . Although it is impossible to infer causality in this study, the association between high CRP levels with low hemoglobin and CRP and VitA levels suggests that inflammation secondary to acute phase response, which is present in individuals with $\mathrm{VL}^{52}$, can partially explain anemia and VitA deficiency.

All individuals with kala-azar had serum zinc levels below the critical limit. The low levels of zinc found in this study can partly be attributed to the parasite-triggered inflammatory process and the host's inability to deal with the infection mainly because of decreased cytokines and enzymes ${ }^{53}$. Although plasma zinc levels were higher in HIV-coinfected patients, all values were below the low limit of normality and were also very close. Although it is not possible to state whether this deficiency was a consequence of the prolonged consumptive state or a risk factor for disease progression, zinc supplementation may be beneficial for the recovery of these individuals. This finding is in line with those described in the literature ${ }^{21,22,54}$. Carbone et al. ${ }^{55}$ showed that children with kala-azar who received zinc supplementation during amphotericin B or pentavalent antimonial treatment showed faster clinical improvement than the group that did not receive zinc supplementation. However, a recent systematic review did not find any study that assessed the effects of oral nutritional supplements in patients with VL treated with antileishmanial drug therapy ${ }^{56}$.

This study showed that a significant proportion of kala-azar patients were malnourished and had lower VitA and zinc levels than the general population. Malnutrition was more prevalent in older 
people and was associated with severe disease in all age groups. Low levels of VitA were associated with nutrition and disease severity. Although zinc was not associated with the disease presentation and severity, it was reduced in all individuals with kala-azar. Finally, these findings led us to speculate whether VitA and zinc replacement may be beneficial as an adjuvant therapy for kala-azar.

\section{ACKNOWLEDGMENTS}

The authors are grateful to the Institute of Tropical Diseases Natan Portela, which provided all support for data collection.

\section{FINANCIAL SUPPORT}

National Council for Scientific and Technological DevelopmentCNPq) Process Number 302571/2015-9.

\section{AUTHORS' CONTRIBUTION}

MJSDM: Conception and design of the study, Acquisition of data, Analysis and interpretation of data, Drafting the article, Final approval of the version to be submitted; MNPS: Conception and design of the study, Acquisition of data; AAP: Conception and design of the study, Acquisition of data; Final approval of the version to be submitted; DNM: Conception and design of the study, Acquisition of data; LAL: Acquisition of data; GSH: Acquisition of data; Final approval of the version to be submitted; PHCR: Acquisition of data; Final approval of the version to be submitted; ISS: Acquisition of data; Final approval of the version to be submitted; ATAA: Acquisition of data; CHNC: Conception and design of the study, Analysis and interpretation of data; Final approval of the version to be submitted; DLC (Corresponding Author): Conception and design of the study, Analysis and interpretation of data, Drafting the article, Final approval of the version to be submitted.

\section{CONFLICT OF INTEREST}

The authors declare that they have no conflict of interest.

\section{ORCID}

Mísia Joyner de Sousa Dias Monteiro: 0000-0002-2863-4094

Maria Nauside Pessoa da Silva: 0000-0001-6040-315X

Adriana de Azevedo Paiva: 0000-0001-5089-4581

Dilina do Nascimento Marreiro: 0000-0002-7550-1403

Liania Alves Luzia: 0000-0001-8317-1398

Gilberto Simeone Henriques: 0000-0002-9110-5427

Patrícia Helen de Carvalho Rondó: 0000-0002-8308-6393

Ingridi de Souza Sene: 0000-0002-2096-0565

Ana Tárcila Alves de Almeida: 0000-0002-5365-7124

Carlos Henrique Nery Costa: 0000-0001-7302-2006

Dorcas Lamounier Costa: 0000-0001-7115-7978

\section{REFERENCES}

1. Costa DL, Rocha RL, de Brito Ferreira Chaves E, de Vasconcelos Batista VG, Costa HL, Nery Costa CH. Predicting death from kalaazar: Construction, development, and validation of a score set and accompanying software. Rev Soc Bras Med Trop. 2016;49(6):728-40.

2. Madalosso G, Fortaleza CM, Ribeiro AF, Cruz LL, Nogueira PA, Lindoso JAL. American Visceral Leishmaniasis: Factors Associated with Lethality in the State of São Paulo, Brazil. Yasuda MAS, editor. J Trop Med. 2012;2012:281572.

3. Lima IP, Müller MC, Holanda TA, Harhay M, Costa CHN, Costa DL. Human immunodeficiency virus/Leishmania infantum in the first foci of urban American visceral leishmaniasis: Clinical presentation from 1994 to 2010. Rev Soc Bras Med Trop. 2013;46(2):156-60.

4. Rijal S, Chappuis F, Sundar S, Lima MA, Olliaro PL, Costa CH, et al. Who Is a Typical Patient with Visceral Leishmaniasis? Characterizing the Demographic and Nutritional Profile of Patients in Brazil, East Africa, and South Asia. Am J Trop Med Hyg. 2011;84(4):543-50.

5. Weiss G. Nutrition and infection. Clin Microbiol Infect. 2018;24(1):8-9.

6. United Nations Children's Fund, World Health Organization WBG. No TitleLevels and trends in child malnutrition: Key findings of the 2018 Edition of the Joint Child Malnutrition Estimates. 2018.

7. Alvar J, Vélez ID, Bern C, Herrero M, Desjeux P, Cano J, et al. Leishmaniasis worldwide and global estimates of its incidence. PLoS One. 2012;7(5):e35671.

8. Nweze JA, Nweze EI, Onoja US. Nutrition, malnutrition, and leishmaniasis. Nutrition. 2020;73:110712.

9. Anstead GM, Chandrasekar B, Zhao W, Yang J, Perez LE MP. Malnutrition alters the innate immune response and increases early visceralization following Leishmania donovani infection. Infect Immun. 2001;69(8):4709-18.

10. Badaro R, Jones TC, Lorenco R, Cerf BJ, Sampaio D, Carvalho EM, et al. A Prospective Study of Visceral Leishmaniasis in an Endemic Area of Brazil. J Infect Dis. 1986;154(4):639-49.

11. Cerf BJ, Jones TC, Badaro R, Sampaio D, Teixeira R, Johnson WD. Malnutrition as a Risk Factor for Severe Visceral Leishmaniasis. J Infect Dis. 1987;156(6):1030-3.

12. Collin S, Davidson R, Ritmeijer K, Keus K, Melaku Y, Kipngetich S, et al. Conflict and Kala-Azar: Determinants of Adverse Outcomes of Kala-Azar among Patients in Southern Sudan. Clin Infect Dis. 2004;38(5):612-9.

13. Tulchinsky TH. Micronutrient Deficiency Conditions: Global Health Issues. Public Health Rev. 2010;32(1):243-55.

14. Taylor CE, Higgs ES. Micronutrients and Infectious Diseases: Thoughts on Integration of Mechanistic Approaches into Micronutrient Research. J Infect Dis. 2000;182(s1):S1-4.

15. Huang Z, Liu Y, Qi G, Brand D, Zheng S. Role of Vitamin A in the Immune System. J Clin Med. 2018;7(9):258.

16. Bono M, Tejon G, Flores-Santibañez F, Fernandez D, Rosemblatt M, Sauma D. Retinoic Acid as a Modulator of T Cell Immunity. Nutrients. 2016;8(6):349.

17. Glasziou PP, Mackerras DE. Vitamin A supplementation in infectious diseases: a meta-analysis. BMJ. 1993;306(6874):366-70.

18. Maciel BLL, Lacerda HG, Queiroz JW, Galvão J, Pontes NN, Dimenstein $\mathrm{R}$, et al. Association of nutritional status with the response to infection with Leishmania chagasi. Am J Trop Med Hyg. 2008;79(4):591-8.

19. Luz KG, Succi RC de M, Torres E. Nível sérico da vitamina A em crianças portadoras de leishmaniose visceral. Rev Soc Bras Med Trop. 2001;34(4):381-4. 
20. Cominetti C, Garrido A, Cozzolino S. Zinc Nutritional Status of Morbidly Obese Patients Before and After Roux-en-Y Gastric Bypass: A Preliminary Report. Obes Surg. 2006;16(4):448-53.

21. Mishra J, Carpenter S, Singh S. Low serum zinc levels in an endemic area of visceral leishmaniasis in Bihar, India. Indian J Med Res. 2010;131:793-8.

22. Lal CS, Kumar S, Ranjan A, Rabidas VN, Verma N, Pandey K, et al. Comparative analysis of serum zinc, copper, magnesium, calcium and iron level in acute and chronic patients of visceral leishmaniasis. J Trace Elem Med Biol. 2013;27(2):98-102.

23. LANPOP. Laboratório de Avaliação Nutricional de Populações. Universidade de São Paulo. Guia para realização do exame de antropometria (Pesquisa Nacional de Saúde - PNS 2017-2019). São Paulo, SP; 2017.

24. Centers for Disease Control and Prevention (CDC). National Center for Health Statistics (NCHS). National Health and Nutrition Examination Survey (NHANES). Anthropometry Procedures Manual. Whashington, DC; 2017

25. Frisancho AR. New norms of upper limb fat and muscle areas for assessment of nutritional status. Am J Clin Nutr. 1981;34:2540-5.

26. Arnaud J, Fortis I, Blachier S, Kia D, Favier A. Simultaneous determination of retinol, $\alpha$-tocopherol and $\beta$-carotene in serum by isocratic high-performance liquid chromatography. J Chromatogr. 1991;572:103-16.

27. WHO. Multicentre Growth Reference Study Group. Serum retinol concentrations for determining the prevalence of vitamin A deficiency in populations. World Heal Organ. 2011;3-7.

28. Gibson R. Assessment of chromium, copper and zinc status. In: Principles of Nutritional Assessment. Oxford University Press: New Yoork, 2005. p. 711-30.

29. Guthrie HA, Picciano MF. Micronutrient mineral. In: Human nutrition. New York: Mosby; 1995. p. 351-7.

30. WHO. Multicentre Growth Reference Study Group. WHO Child Growth Standards: Length/height-for-age, weight-for-age, weight-forlength, weight-for-height and body mass index-for-age: Methods and development. Geneva: World Heal Organ. 2006;312.

31. WHO. World Helath Organization. WHO child growth standards : head circumference-for-age, arm circumference-for-age, triceps skinfold-forage and subscapular skinfold-for-age : methods and development. World Health Organization. 2007. p. 217.

32. Brasil. Miniistério da Saude. Secretaria de Atenção à Saúde. Departamento de atenção Básica. Orientações para a coleta e análise de dados antropométricos em serviços de saúde: Norma Técnica do Sistema de Vigilância Alimentar e Nutricional - SISVAN / Ministério da Saúde, Secretaria de Atenção à Saúde, Departamento de Atenção Básica. Ministério da Saúde. 2011. 76 p.

33. Tekalign S, Adera C, Den Boer M, Miecha H, Zewde A, Mulugeta D, et al. Clinical features and treatment outcomes of visceral leishmaniasis patients admitted to three centers in Oromia, Ethiopia. J Infect Dev Ctries. 2020;14(06.1):42S-47S.

34. Guedes DL, Medeiros Z, Dionísio da Silva E, Martins de Vasconcelos AV, Santana da Silva M, Lopes da Silva MA, et al. Visceral Leishmaniasis in Hospitalized HIV-Infected Patients in Pernambuco, Brazil. Am J Trop Med Hyg. 2018;99(6):1541-6.

35. Zacarias DA, Rolão N, de Pinho FA, Sene I, Silva JC, Pereira TC, et al. Causes and consequences of higher Leishmania infantum burden in patients with kala-azar: a study of 625 patients. Trop Med Int Heal. 2017;22(6):679-87.
36. Mengesha B, Endris M, Takele Y, Mekonnen K, Tadesse T, Feleke A, et al. Prevalence of malnutrition and associated risk factors among adult visceral leishmaniasis patients in Northwest Ethiopia: a cross sectional study. BMC Res Notes. 2014;7(1):75.

37. Giefing-Kröll C, Berger P, Lepperdinger G, Grubeck-Loebenstein B. How sex and age affect immune responses, susceptibility to infections, and response to vaccination. Aging Cell. 2015;14(3):309-21.

38. Costa CHN, Pereira HF, Araújo MV. Epidemia de leishmaniose visceral no Estado do Piauí, Brasil, 1980-1986. Rev Saude Publica. 1990;24(5):361-72.

39. Luz JGG, Naves DB, de Carvalho AG, Meira GA, Dias JVL, Fontes CJF. Visceral leishmaniasis in a Brazilian endemic area: An overview of occurrence, HIV coinfection and lethality. Rev Inst Med Trop Sao Paulo. 2018;6:1-9.

40. Reis LL dos, Balieiro AA da S, Fonseca FR, Gonçalves MJF. Changes in the epidemiology of visceral leishmaniasis in Brazil from 2001 to 2014. Rev Soc Bras Med Trop. 2017;50(5):638-45.

41. Sarkari B, Naraki T, Ghatee MA, Abdolahi Khabisi S, Davami MH. Visceral Leishmaniasis in Southwestern Iran: A Retrospective ClinicoHematological Analysis of 380 Consecutive Hospitalized Cases (19992014). Speletas M, editor. PLoS One. 2016;11(3):e0150406.

42. Ahmed MAA, Ahmed AA, Omar SM, Adam GK, Abdallah TM, Ali AAA. Epidemiology of visceral leishmaniasis among children in Gadarif hospital, eastern Sudan. BMC Public Health. 2016;16(1):1-4.

43. Diro E, Lynen L, Gebregziabiher B, Assefa A, Lakew W, Belew Z, et al. Clinical aspects of paediatric visceral leishmaniasis in North-west Ethiopia. Trop Med Int Heal. 2015;20(1):8-16.

44. Weldeabezgi AH, Mulugetan A, Haileslassie K, Mruts KB GA. Nutritional Status of Adult Kala-azar Patients and Associated Factors in North West, Ethiopia. J Nutr Food Sci. 2017;07(04).

45. Herwaldt BL. Leishmaniasis. Lancet. 1999 Oct 2;354(9185):1191-9. Available from: http://www.ncbi.nlm.nih.gov/pubmed/17230422

46. Feleke BE. Nutritional status of visceral leishmaniasis patients: A comparative cross-sectional study. Clin Nutr ESPEN. 2019;33:139-42.

47. Zijlstra EE, Ali MS, El-Hassan AM, El-Toum IA, Satti M, Ghalib HW, et al. Kala-azar in displaced people from southern Sudan: epidemiological, clinical and therapeutic findings. Trans R Soc Trop Med Hyg. 1991;85(3):365-9.

48. Lima Maciel BL, Valverde JG, Rodrigues-Neto JF, Freire-Neto F, Keesen TSL, Jeronimo SMB. Dual Immune Modulatory Effect of Vitamin A in Human Visceral Leishmaniasis. Piccirillo CA, editor. PLoS One. 2014;9(9):e107564.

49. Yang C, Chen J, Guo N, Liu Z, Yun C, Li Y, et al. Comparison on the status of vitamin A in 6- to 13-year-old children between 2002 and 2012 in China. Nutr J. 2015;15(1):50.

50. Ministério da Saúde. Manual de Condutas Gerais do Programa Nacional de Suplementação de Vitamina A. 2013;34.

51. Mazumder S, Taneja S, Bhatia K, Yoshida S, Kaur J, Dube B, et al. Efficacy of early neonatal supplementation with vitamin A to reduce mortality in infancy in Haryana, India (Neovita): a randomised, doubleblind, placebo-controlled trial. Lancet. 2015;385(9975):1333-42.

52. Costa DL, Rocha RL, Carvalho RMA, Lima-Neto AS, Harhay MO, Costa CHN, et al. Serum cytokines associated with severity and complications of kala-azar. Pathog Glob Health. 2013;107(2): 78-87.

53. Souza CC, Barreto T de O, da Silva SM, Pinto AWJ, Figueiredo MM, Ferreira Rocha OG, et al. A potential link among antioxidant enzymes, 
histopathology and trace elements in canine visceral leishmaniasis. Int J Exp Pathol. 2014;95(4):260-70.

54. Van Weyenbergh J, Santana G, D’Oliveira A, Santos AF, Costa CH, Carvalho EM, et al. Zinc/copper imbalance reflects immune dysfunction in human leishmaniasis: An ex vivo and in vitro study. BMC Infect Dis. 2004;4:1-7.

55. Carbone DCB, Zanoni LZG, Cônsolo FZ, Sanches SC, Reis VQ dos, Muller K de TC, et al. Potential role of zinc in the visceromegaly regression and recovery of hematological parameters during treatment of visceral leishmaniasis in children from an endemic area. Rev Inst Med Trop Sao Paulo. 2018;60.

56. Custodio E, López-Alcalde J, Herrero M, Bouza C, Jimenez C, Storcksdieck genannt Bonsmann $\mathrm{S}$, et al. Nutritional supplements for patients being treated for active visceral leishmaniasis. Cochrane Database Syst Rev. 2018;2018(3):CD012261. 